\title{
DESENVOLVIMENTO TERRITORIAL NO MUNICÍPIO DE SANTA TERESA (ES): Discussões acerca da Sustentabilidade no Circuito Caravaggio
}

\author{
Rosa Cristina Monteiro' \\ Carlos Alexandre Volpii \\ Sílvio de Oliveira Alvesiii \\ Victorio Birchler Toniniv \\ Tiago Badre Marinov
}

\begin{abstract}
Resumo: este trabalho apresenta resultados de pesquisa realizada no município de Santa Teresa, estado do Espírito Santo - Brasil, com o objetivo de avaliar os níveis de sustentabilidade envolvidos na implantação de um circuito turístico criado para a promoção de desenvolvimento territorial no meio rural - o "Circuito Caravaggio". As atrações que compõem o circuito foram cartografadas com apoio da Plataforma Vicon SAGA e deram origem a três cartogramas que possibilitaram a identificação, descrição e análise das experiências de ocupação socioespacial que formam o circuito, e que foram em seguida classificadas conforme os níveis de sustentabilidade. Três experiências paradigmáticas foram destacadas: um empório com fabricação e venda de produtos alimentares e artesanais, cuja sustentabilidade foi considerada fraca; uma rampa de voo livre com tratamento paisagístico, cuja sustentabilidade foi considerada de fraca a forte e um clube campestre com intenso patrimônio natural e potencialidade para adquirir níveis de sustentabilidade muito fortes Concluiu-se que o Circuito tem atendido a seu propósito de promover o desenvolvimento, porém tensiona-se pela entrada de vetores de urbanização que colocam em risco a continuidade da proposta inicial do projeto. De maneira conclusiva, aponta-se a necessidade de construção de fóruns de participação da população local com
\end{abstract}

\footnotetext{
'Docente Titular do Departamento de Psicologia da Universidade Federal Rural do Rio de Janeiro (DPSI/UFRuraIRJ), rosacristina.monteiro@gmail.com, https://orcid.org/0000-0002-3002-4682.

iiMestrando do Programa de Pós-Graduação em Educação Agrícola da Universidade Federal Rural do Rio de Janeiro (PPGEA/UFRuraIRJ), Técnico Administrativo em Educação do Instituto Federal do Espírito Santo (IFES), cvolpi2004@gmail.com, https://orcid.org/0000-0002-4683-0531.

iiiMestrando do Programa de Pós-Graduação em Educação Agrícola da Universidade Federal Rural do Rio de Janeiro (PPGEA/UFRuraIRJ), Técnico Administrativo em Educação do Instituto Federal do Espírito Santo (IFES), soa.orto@gmail.com, https://orcid.org/0000-0002-7855-7760.

iv Mestrando do Programa de Pós-Graduação em Educação Agrícola da Universidade Federal Rural do Rio de Janeiro (PPGEA/UFRuralRJ), Técnico Administrativo em Educação do Instituto Federal do Espírito Santo (IFES), victorio94.bt@gmail.com, https://orcid.org/0000-0002-1548-7419.

$\checkmark$ Docente do Departamento de Geografia Universidade Federal Rural do Rio de Janeiro (GE/UFRuralRJ), tiagomarino@ufrri.br, https://orcid.org/0000-0002-8047-0170.
} 
envolvimento dos poderes públicos, de maneira a fomentar discussões quanto à exploração turística de maneira sustentável.

Palavras-chave: território; turismo rural; cartografias sociais; sustentabilidade; políticas públicas.

\title{
TERRITORIAL DEVELOPMENT IN SANTA TERESA/ES: DISCUSSIONS ON SUSTAINABILITY IN CARAVAGGIO CIRCUIT
}

\begin{abstract}
: this work presents the results of a research carried out in the municipality of Santa Teresa, state of Espírito Santo - Brazil, with the objective of evaluating sustainability levels concerning the implementation of a tourist circuit created, at first, to promote territorial development in rural areas - the "Circuit Caravaggio". The attractions located into the circuit were mapped with the support of Vicon SAGA Platform and originated three cartograms that enabled the identification, description and analysis of the socio-spatial occupation experiences that make up the circuit, which were then classified according to their respective sustainabilitylevels. Three paradigmatic experiences were highlighted: an emporium presenting the manufacture and sale of local food and craft products, whose sustainability was considered weak; a hang-gliding ramp with landscape treatment, whose sustainability was considered weak to strong; and a country club with intense natural heritage and the potential to acquire very strong levels of sustainability. The conclusion is that the Circuit has served its purpose of promoting development, however, it is strained by urbanization vectors'pressure that jeopardize the initial project proposalstrength. In a conclusive manner, researchers point out a demand to assemble participatory forums with local population along with public authorities, in order to foster discussions regarding tourism exploration in a sustainable way.

Keywords: territory; rural tourism; social cartographies; sustainability; public policy.
\end{abstract}

\section{DESARROLLO TERRITORIAL EN SANTA TERESA/ES: DISCUSIONES SOBRE SOSTENIBILIDAD EN EL CIRCUITO CARAVAGGIO}

Resumen: este trabajo presenta los resultados de una investigación realizada enelmunicipio de Santa Teresa, estado de Espírito Santo Brasil, conel objetivo de evaluarlos niveles de sostenibilidad involucrados enlaimplantación de un circuito turístico creado para promover eldesarrollo territorial enlas zonas rurales: el "Circuito Caravaggio". Lasatracciones que componenel circuito se mapearonconelapoyo de la Plataforma Vicon SAGA y dieron lugar a tres cartogramas que permitieronlaidentificación, descripción y análisis de las experiencias de ocupación socioespacial que componenel circuito, que luego se clasificaronsegúnlos niveles de sostenibilidad. Se destacarontres experiencias paradigmáticas: unemporioconlafabricación y venta de alimentos y 
productosartesanales, cuyasostenibilidad se consideró débil; una rampa de vuelo libre contratamientopaisajístico, cuyasostenibilidad se consideraba débil a fuerte y un club de campo conunpatrimonio natural intenso y el potencial de adquirir niveles muyfuertes de sostenibilidad. sin embargo, se veafectado por la entrada de vectores de urbanización que ponenenpeligrolacontinuidad de lapropuesta inicial delproyecto. De maneraconcluyente, se señalalanecesidad de construir foros para laparticipación de lapoblación local conlaparticipación de las autoridades públicas, conelfin de fomentar lasdiscusiones sobre laexploracióndel turismo de manerasostenible.

Palabras clave: territorio; turismo rural; cartografíassociales;

\section{Introdução}

O presente artigo apresenta resultados de pesquisa conduzida no município de Santa Teresa - Espírito Santo, ao longo do ano de 2019, com o objetivo de avaliar os níveis de sustentabilidade alcançados na implantação e promoção de um circuito turístico no meio rural, criado no marco das políticas públicas de desenvolvimento territorial sustentável. Ao realizar a investigação, inserimo-nos em um campo profícuo de discussões e práticas que incidem sobre o meio rural, especialmente a partir dos anos 1980, quando os espaços sociais foram reconfigurados e ressignificados em escala planetária. Programas de turismo foram concebidos e implementados em todo o mundo na perspectiva de promover o desenvolvimento nos ambientes rurais, com marcos conceituais e operacionais girando em torno das noções de território e sustentabilidade.

É sabido que a noção de território apresenta uma pletora de significados, com as definições oscilando de um polo estritamente materialista a outro puramente idealista. No polo materialista, o território é identificado com a própria natureza e no polo idealista identifica-se território e cultura.

Em nosso trabalho assumimos uma terceira posição, intermediária, que consiste em compreender que o território é relacional, incorporando um conjunto de relações sociais e a dinâmica complexa entre os processos sociais e o espaço material (HAESBAERT, 2011). Com este entendimento de território, ao refletir e agir sobre 
determinada fração do espaço físico e social, devemos considerar que tais ações definem territórios, que por sua vez anulam ou transformam outros territórios, sobre a mesma base material de produção. Neste sentido, o amálgama formado da relação natureza-cultura dá origem a processos de territorializações-desterritorializaçõesreterritorializações pelas ações, coordenadas ou não, de diferentes atores sociais.

Promover o desenvolvimento territorial, especialmente no mundo rural, é favorecer a emergência de relações harmoniosas, em que os atores sociais alcancem os mais elevados níveis de autonomia econômica, social e cultural, preservando o espaço natural que dá suporte à própria vida.

A questão da sustentabilidade foi instaurada a partir dos anos 1980, quando uma comissão das Nações Unidas elaborou o Relatório Brundtland (CMMAD, 1991), apresentando institucionalmente o alerta de que as gerações futuras correm o risco de não encontrar condições adequadas a sua sobrevivência, se as ações desenvolvimentistas de hoje não atentarem para a finitude da base material de produção de vida no planeta. Desde então a discussão sobre a sustentabilidade não parou, provocando a emergência de inúmeras referências.

Adotamos aqui, a revisão realizada por MONTEIRO (2012), que analisa a produção histórica do conceito de desenvolvimento sustentável, identificando três eras: PréEstocolmo (até 1972), Estocolmo-Rio (1972-1992), Pós-Rio (1992 em diante); após descrever detalhadamente a evolução dos discursos e práticas ao longo destes períodos, a autora chega a uma síntese. Para ela, o problema do desenvolvimento sustentável consiste em fazer com que uma região economicamente pobre cresça com padrões socialmente justos e com os cuidados relativos aos patrimônios naturais e culturais locais. Ou seja, deve-se estimular o crescimento sem deteriorar as relações sociais e sem devastar os ecossistemas persistentes/resistentes.

\section{Quadro teórico de referência para a noção de sustentabilidade: o sistema Pearce}


Desde sua primeira definição no Relatório Brundtland até data recente, o principal desdobramento do conceito de desenvolvimento sustentável parece ter sido no sentido de introduzir múltiplas dimensões em sua definição. Em meio à profusão de textos e referências, elegemos como paradigma em nosso trabalho a elaboração feita por Pearce, em 1993, quando criou uma tipologia organizando as experiências e programas de desenvolvimento sustentável em quatro categorias - tecnocentrismo/cornucopiana, adaptativa, comunalista e ecocentrismo/ecologia profunda -, diferenciadas em três dimensões: a) o tipo de economia; b) as estratégias de gestão; c) a ética envolvida. Seu trabalho apresenta um importante valor analítico e mantém-se atual, já transcorridos alguns anos de sua elaboração (STOFFEL; COLOGNESE, 2015). A síntese de Pearce, com a qual analisaremos nossos resultados, é apresentada na tabela a seguir.

Tabela 1 - Diferentes ideologias ambientais e níveis de sustentabilidade

\begin{tabular}{|c|c|c|c|c|}
\hline & $\begin{array}{c}\text { Tecnocentrismo/ } \\
\text { Cornucopiana }\end{array}$ & Adaptativa & Comunalista & $\begin{array}{l}\text { Ecocentrismo/ } \\
\text { Ecologia Profunda }\end{array}$ \\
\hline $\begin{array}{c}\text { Rótulo } \\
\text { Ambiental }\end{array}$ & $\begin{array}{l}\text { Exploração de recursos; } \\
\text { orientação pelo } \\
\text { crescimento. }\end{array}$ & $\begin{array}{l}\text { Conservacionismo } \\
\text { dos recursos; } \\
\text { posição gerencial. }\end{array}$ & Preservação de recursos & $\begin{array}{l}\text { Preservacionismo } \\
\text { profundo }\end{array}$ \\
\hline $\begin{array}{l}\text { Tipos de } \\
\text { Economia }\end{array}$ & $\begin{array}{l}\text { Economia antiverde; } \\
\text { livre mercado. }\end{array}$ & $\begin{array}{l}\text { Economia verde; } \\
\text { mercado verde } \\
\text { conduzido por } \\
\text { instrumentos de } \\
\text { incentivos } \\
\text { econômicos. }\end{array}$ & $\begin{array}{l}\text { Economia verde profunda. } \\
\text { Economia estacionária; } \\
\text { regulação } \\
\text { macroambiental. }\end{array}$ & $\begin{array}{l}\text { Economia verde muito } \\
\text { profunda; forte regulação } \\
\text { para minimizar a tomada } \\
\text { de recursos. }\end{array}$ \\
\hline & Objetivo econômico, & & & \\
\hline $\begin{array}{c}\text { Estratégia de } \\
\text { Gestão }\end{array}$ & $\begin{array}{l}\text { maximização do } \\
\text { crescimento econômico. } \\
\text { Considera que o livre } \\
\text { mercado, em conjunto } \\
\text { com o progresso } \\
\text { tecnológico, pode } \\
\text { possibilitar a eliminação } \\
\text { das restrições relativas aos } \\
\text { limites e à escassez. }\end{array}$ & $\begin{array}{l}\text { Modificação do } \\
\text { crescimento } \\
\text { econômico, } \\
\text { norma do capital } \\
\text { constante, alguma } \\
\text { mudança de } \\
\text { escala. }\end{array}$ & $\begin{array}{l}\text { Crescimento econômico e } \\
\text { populacional nulo. } \\
\text { Perspectiva sistêmica, } \\
\text { saúde do todo } \\
\text { (ecossistema). }\end{array}$ & $\begin{array}{l}\text { Reduzida escala da } \\
\text { economia e da população. } \\
\text { Imperativa mudança de } \\
\text { escala. }\end{array}$ \\
\hline Ética & $\begin{array}{l}\text { Direitos e interesses dos } \\
\text { indivíduos } \\
\text { contemporâneos; valor } \\
\text { instrumental na natureza. }\end{array}$ & $\begin{array}{l}\text { Equidade intra e } \\
\text { intergeracional } \\
\text { (respeitante à } \\
\text { repartição); valor } \\
\text { instrumental na } \\
\text { natureza. }\end{array}$ & $\begin{array}{l}\text { Interesse coletivo } \\
\text { sobrepõe o interesse } \\
\text { individual; valor primário } \\
\text { dos ecossistemas e valor } \\
\text { secundário para suas } \\
\text { funções e serviços. }\end{array}$ & $\begin{array}{l}\text { Bioética (direitos e } \\
\text { interesses conferidos a } \\
\text { todas as espécies), valor } \\
\text { intrínseco da natureza. }\end{array}$ \\
\hline
\end{tabular}




$\begin{array}{cllll}\begin{array}{c}\text { Grau de } \\ \text { Sustentabilid } \\ \text { ade }\end{array} & \begin{array}{l}\text { Sustentabilidade muito } \\ \text { fraca }\end{array} & \begin{array}{l}\text { Sustentabilidade } \\ \text { fraca }\end{array} & \text { Sustentabilidade forte } & \begin{array}{l}\text { Sustentabilidade muito } \\ \text { forte }\end{array}\end{array}$

Fonte: STOFFEL e COLOGNESE (2015)

\section{O contexto da pesquisa - Santa Teresa e o Circuito Caravaggio}

No Brasil, entre 1990 e 2007, o turismo rural se difundiu veloz e aleatoriamente, o que provocou a ação de alguns entes e organizações sociais no sentido de normatizar e garantir a sustentabilidade das iniciativas em curso. Foi dentro desta perspectiva que o SEBRAE/ES, em parceria com a SEDETUR - Secretaria de Desenvolvimento Econômico e Turístico do Espírito Santo e BNDES - Banco de Desenvolvimento do Espírito Santo realizou um trabalho com a finalidade de conhecer e organizar as potencialidades turísticas dos municípios do Espírito Santo em 2004.

No relatório final do levantamento, Santa Teresa é caracterizada da seguinte maneira: [o município] possui área total de $671,94 \mathrm{Km}^{2}$. Dos grupos étnicos, a maioria é branca (76,77\% do total da população), em função da contribuição dos imigrantes italianos que para lá seguiram no século XIX (MATTOS; NUNES; SOBRINHO, 2013).

A contribuição cultural do imigrante italiano se mantém na gastronomia típica do município, entre salgados, doces e bebidas, principalmente os vinhos, além da produção da arquitetura urbana e da rural. A economia é basicamente agroindustrial onde se destaca a produção cafeeira. O comércio de madeira é a segunda atividade econômica mais representativa.

A região montanhosa do município apresenta vales e serras que contribuem para a formação de um complexo hidrográfico e apresenta configurações rochosas e nascentes. Como parte do suporte geográfico, o município possui em seu território importantes áreas de reservas naturais, destacando: Estação Biológica de Santa Lúcia Reserva Biológica Augusto Ruschi, Parque Natural Municipal de São Lourenço, Parque Natural Municipal Goiapaba-açu e Área de Proteção Ambiental Goiapaba-açu. 
Das regiões do município, uma delas foi destacada por suas potencialidades turísticas: o Vale do Caravaggio, localizado em Vargem Alta, área não urbana às margens da Rodovia ES-261, distando nove quilômetros da sede do município, com acesso rodoviário parcialmente pavimentado, sinalizado e em bom estado de conservação. $O$ vale é formado por cordilheiras que chegam a 900m de altura e abriga a Capela de Nossa Senhora do Caravaggio, construída por imigrantes italianos. Em dias claros, dali se pode avistar a cidade de Colatina.

A partir desse diagnóstico das potencialidades turísticas da região se implantou o Circuito Caravaggio, que hoje está consolidado em ampla folheteria, recebendo visitantes de todo o Brasil e exterior, e que constitui o contexto de nossa pesquisa.

O Circuito se inicia no antigo hospital, situado ainda na área urbana da cidade e se estende por 14 quilômetros, basicamente por estradas de terra batida que, no momento da pesquisa, se encontravam em boas condições. A vegetação do circuito se divide basicamente entre mata fragmentos do bioma de mata atlântica nativa e significativas plantações de eucaliptos para fins comerciais. A Figura 1 apresenta o croqui situando localizações de acesso e atrações do "Circuito".

Figura 1 - Croqui de localização de acesso e atrações do "Circuito Caravaggio" município de Santa Teresa (ES) 


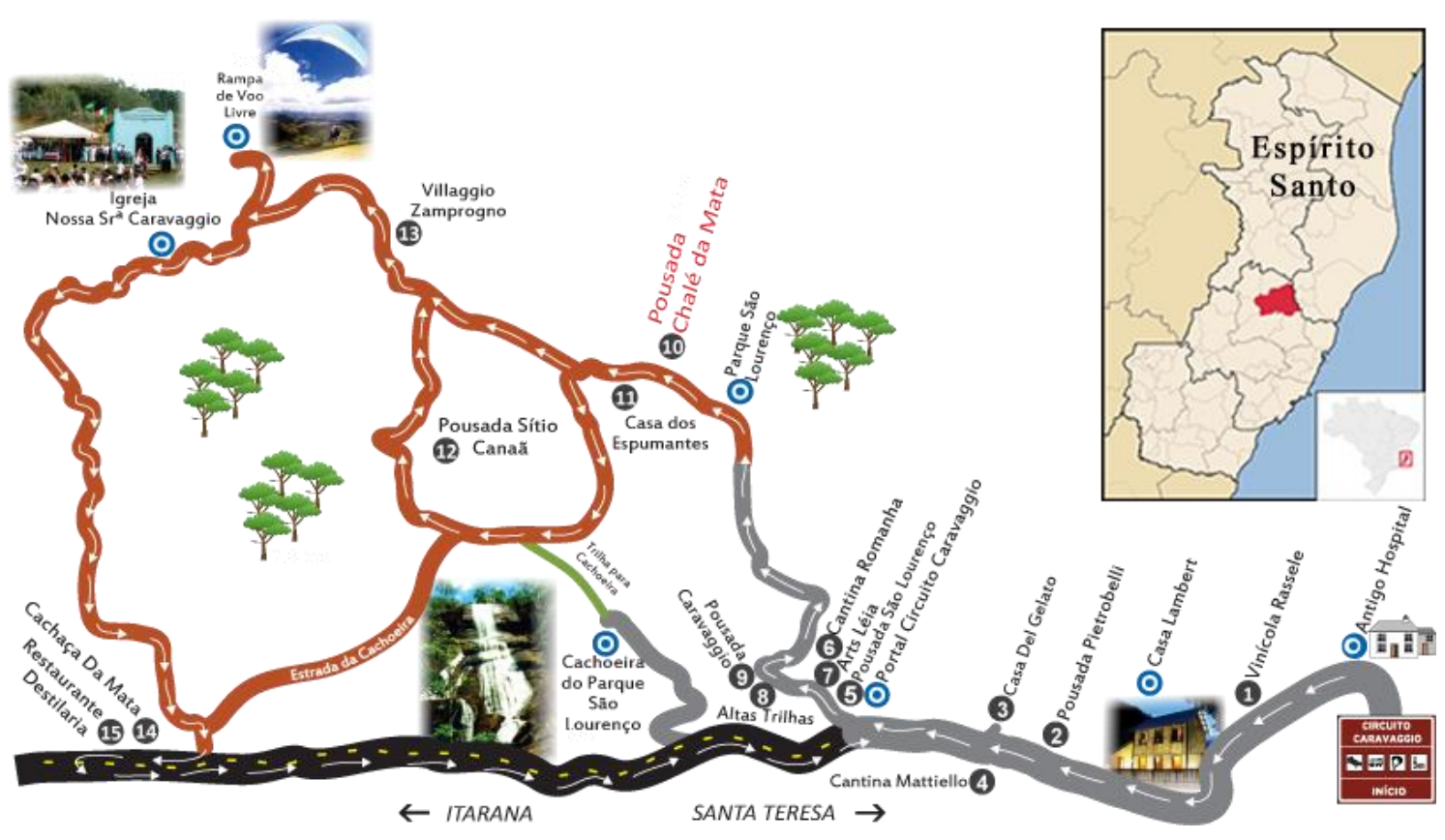

Fonte: Adaptado de SLPC (2020).

\section{Metodologia de construção de dados - cartografias socioambientais}

Utilizamos a metodologia de elaboração de cartografias socioambientais, na qual o ato de cartografar implica em se deslocar entre territórios, formando deles representações e afetos, buscando responder ou ressignificar uma questão problematizadora: no nosso caso, descrever e analisar o nível de sustentabilidade das experiências turísticas propiciadas no Circuito Caravaggio.

A cartografia social (diferentemente da cartografia tradicional, que busca representar graficamente uma área geográfica) é uma ferramenta participativa que busca a caracterização de um território por meio de uma análise flexível e crítica. PRADO FILHO e TETI (2013) afirmam:

Assim, a cartografia social aqui descrita liga-se aos campos de conhecimento das ciências sociais e humanas e, mais que mapeamento físico, trata de 
movimentos, relações, jogos de poder, enfrentamentos entre forças, lutas, jogos de verdade, enunciações, modos de objetivação, de subjetivação, de estetização de si mesmo, práticas de resistência e de liberdade. Não se refere a método como proposição de regras, procedimentos ou protocolos de pesquisa, mas, sim, como estratégia de análise crítica e ação política, olhar crítico que acompanha e descreve relações, trajetórias, formações rizomáticas, a composição de dispositivos, apontando linhas de fuga, ruptura e resistência (PRADO FILHO; TETI, 2013).

Um grupo formado por oito pesquisadores ligados ao Instituto Federal de Educação,

Ciência e Tecnologia do Espírito Santo e à Universidade Federal Rural do Rio de Janeiro, com formação universitária em diferentes áreas, realizou quatro incursões ao território do Circuito Caravaggio, fazendo registros com o uso da fotografia, da observação participante e de entrevistas abertas.

A plataforma Vicon SAGA para apoio à coleta de dados da pesquisa em campo
“Na pesquisa aqui relatada adotamos a noção de sustentabilidade como utopia para o século XXI, como força social capaz de opor-se ao industrialismo desenfreado em todos os setores das atividades humanas e seus respectivos corolários de impactos negativos sobre a continuação da vida".

Os dados construídos por estes meios foram referenciados pelo enquadramento teórico da pesquisa e por uma plataforma de georreferenciamento: a plataforma Vicon SAGA ${ }^{i}$, que nos ofereceu os meios de organizar, tratar e apresentar a produção em seus contextos taxonômico e territorial, transformando os dados em informações geoincluídas, compatíveis com os objetivos definidos.

' Plataforma Vigilância e Controle (Vicon SAGA) - https://viconsaga.com.br/. 
Concebido no ano 2.000 , por meio de uma iniciativa $100 \%$ nacional e livre de custos, a Plataforma Vicon SAGA vem sendo desenvolvida e aprimorada constantemente pelo Laboratório de Geoprocessamento da UFRJ - LAGEOP/UFRJ em parceria com o Laboratório de Geoprocessamento Aplicado da Universidade Federal Rural do Rio de Janeiro (LGA/UFRRJ), diferencia-se das demais aplicações existentes por sua flexibilidade na elaboração de formulários. A Plataforma também contempla a capacidade de inserção de conteúdo multimídia, como fotos e vídeos, e quaisquer arquivos digitais relacionados ao fenômeno retratado (MARINO et al., 2014).

Ao final de cada saída, o grupo de pesquisadores/cartógrafos se reuniu para construir o cartograma das situações percebidas, vividas e registradas, discutindo, analisando-as e planejando a saída seguinte. Os dados construídos a cada saída foram sendo incorporados nos resultados das saídas seguintes até que o grupo considerou que o material já era suficiente para finalizar um cartograma sobre o desenvolvimento territorial no Circuito Caravaggio e seus principais impactos sociais e ambientais.

\section{Resultados encontrados: cartogramas de um lugar em movimento}

Ao longo das sucessivas incursões realizadas no território do Circuito Caravaggio, alguns pontos foram sinalizados, descritos e fotografados, formando cartogramas da região. A primeira saída configurou o circuito com ênfase no turismo, segundo a primeira proposta de desenvolvimento que especializou essa experiência. Nesse cartograma, destaca-se a presença dos produtores de vinhos, cachaças e embutidos, e as perspectivas panorâmicas que conformam paisagens.

\section{Figura 2 - Primeira Deriva no Circuito Caravaggio}




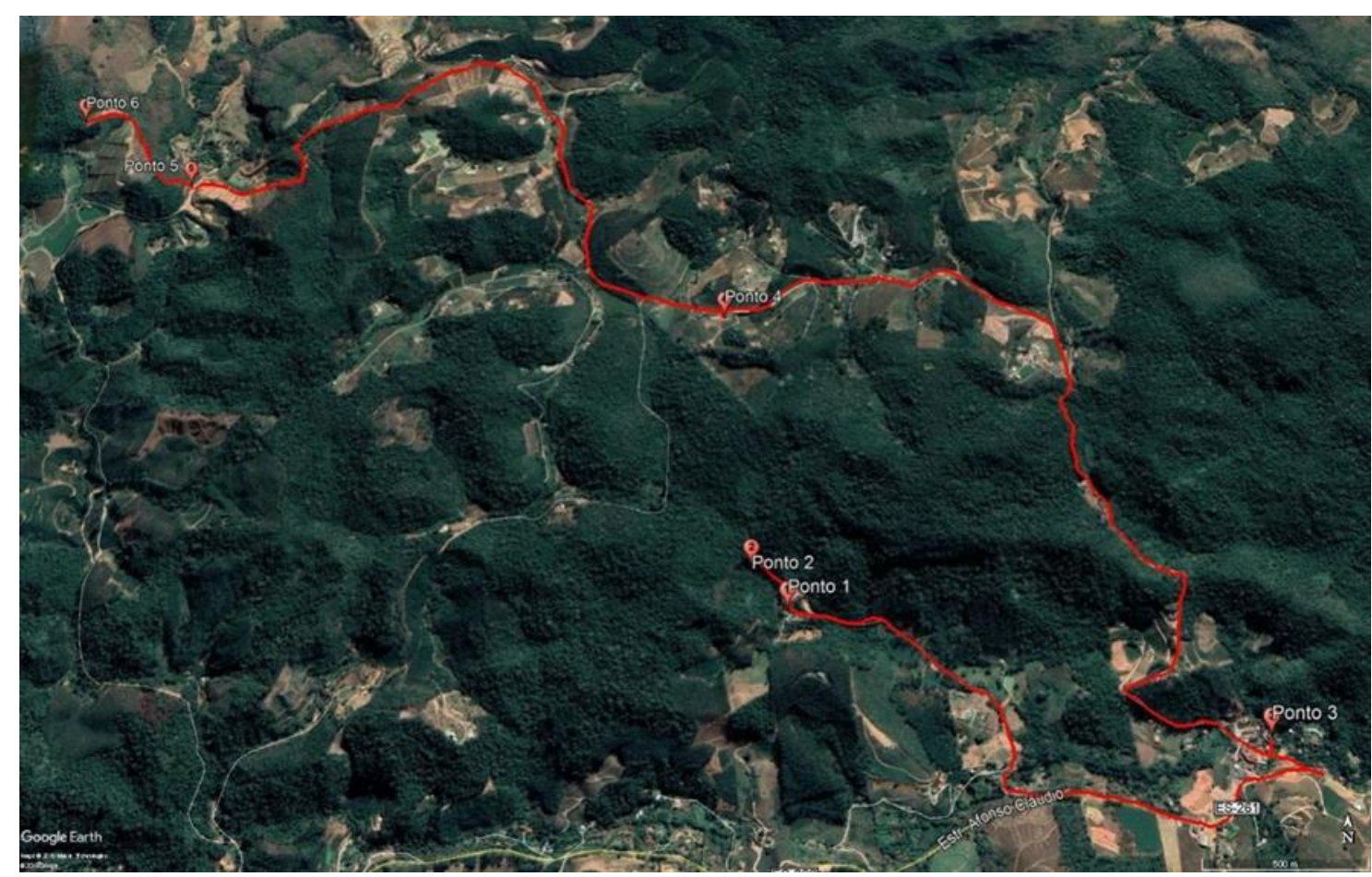

Ponto 1 - Sede do Country Clube de Santa Teresa; Ponto 2 - Cachoeira do Country Clube de Santa Teresa; Ponto 3 - RistoranteRomanha e Produtos Artesanais; Ponto 4 - Casa dos Espumantes; Ponto 5 - Igreja Nossa Senhora do Caravaggio; Ponto 6 - Black House.

O território do Circuito Caravaggio mostrou-se desde o início fortemente atraente para experiências turísticas, pela diversidade natural e cultural ali encontradas. Entrevistas realizadas nos pontos de paradas com produtores e trabalhadores locais evidenciaram uma receptividade própria dos lugares com boas experiências turísticas. Em todos os pontos de visitação e venda os pesquisadores foram bem acolhidos e convidados a conhecer e degustar os produtos expostos.

Figura 3 - Áreas de degradação do Circuito Caravaggio 


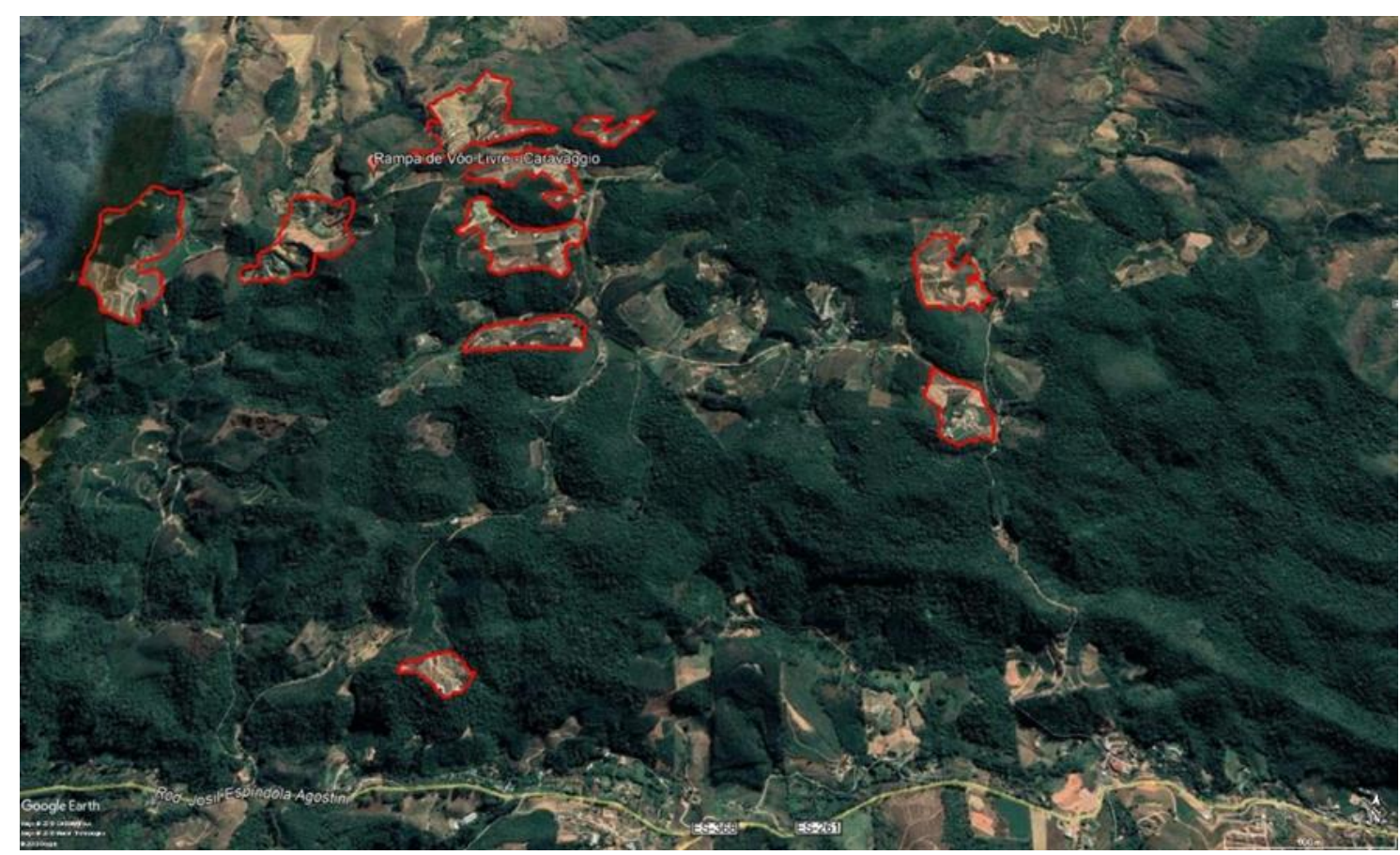

Ficamos assim diante de dois cenários, apontando em direções contrárias: por um lado, o cenário que emerge do plano inicial na criação do Circuito, com potencialidade para efetivamente promover o desenvolvimento sustentável (representados na Figura 2), e por outro, outro cenário, formado pelas consequências inesperadas do próprio desenvolvimento turístico, emergente da valorização territorial e consequente especulação imobiliária (representados na Figura 3).

Contudo, durante esta saída, e após análise dos registros realizados, pontuou-se um aspecto que contrasta com a proposta inicial de sustentabilidade, na ocorrência de grandes loteamentos e movimentos de terra, com aspecto de destruição de paisagem e riscos ambientais. Sendo assim, após a primeira descrição do circuito e tendo como definição a territorialização para fins turísticos, o grupo planejou e empreendeu uma segunda deriva cartográfica para localizar e analisar os pontos de tensão territorial.

A Figura 4 representa a rota percorrida durante a segunda deriva no Circuito Caravaggio.

\section{Figura 4 - Rota percorrida durante a segunda deriva no Circuito Caravaggio}




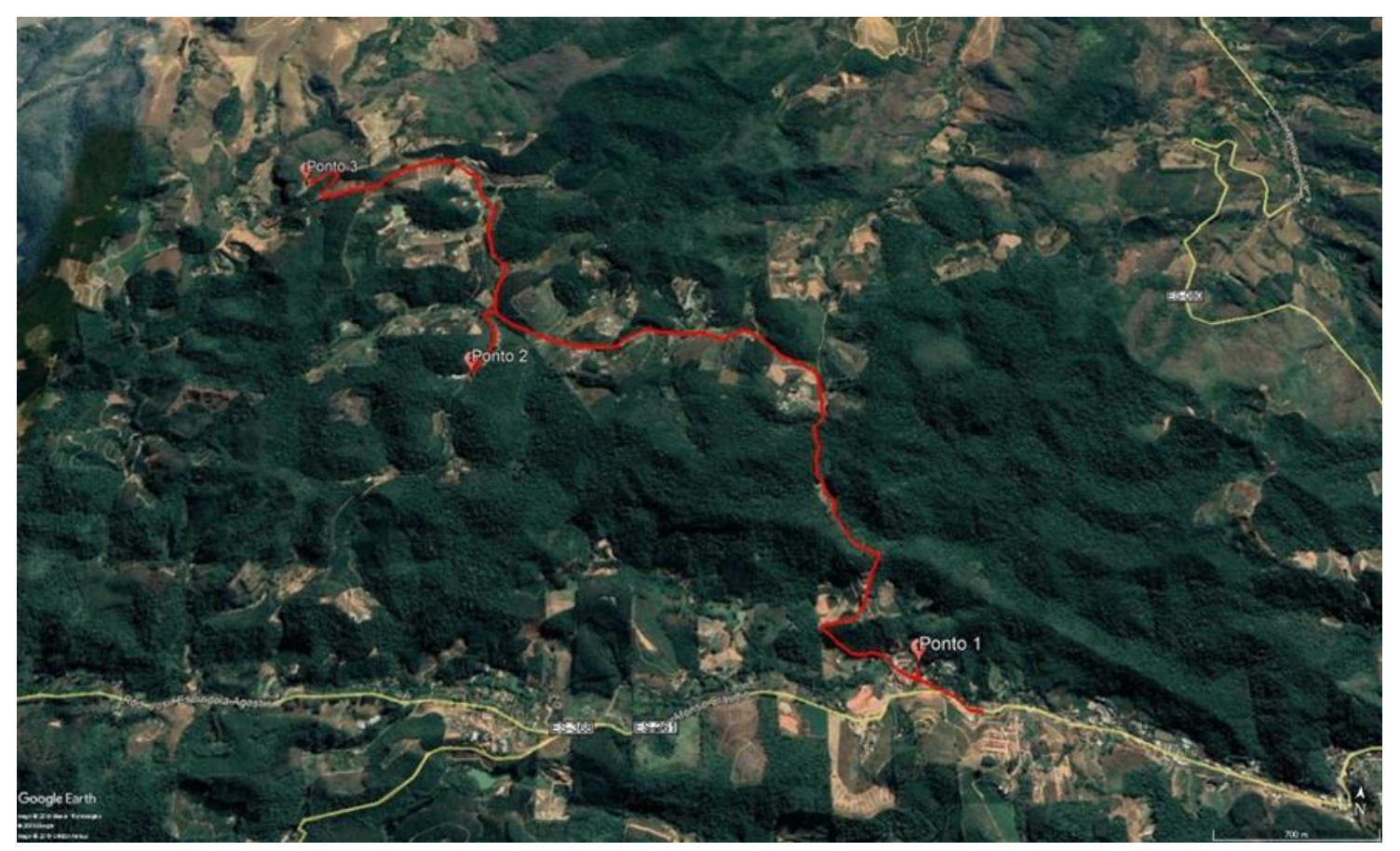

No trabalho de campo seguinte, outras experiências foram detectadas e cartografadas, já não mais com o território turístico em evidência e sim com a questão da ocupação territorial decorrente da especulação imobiliária, que, em muitos casos, ameaça à integridade ambiental, em várias dimensões: desde o comprometimento da paisagem, passando pelo risco de erosão nas movimentações de terra feitas de modo descontrolado e inadequado, até o problema principal do esgotamento das fontes de água que abastecem a pequena produção do entorno. Desta incursão ao campo formouse um segundo cartograma indicando os lugares de maior fragilidade.

Dando prosseguimento à pesquisa, foram então eleitos alguns pontos do circuito (apresentados a seguir) que se mostraram mais potentes na promoção do desenvolvimento sustentável, com a compreensão de que são estas experiências que devem realmente ser valorizadas nos projetos em curso, e naqueles a serem futuramente implantados.

As cartografias seguintes aprofundaram as leituras territoriais anteriores e algumas experiências de ocupação do espaço foram escolhidas como exemplares para indicar os 
diferentes níveis de sustentabilidade que caracterizam hoje o território do Circuito Caravaggio, segundo a classificação de Pearce.

Chegou-se assim a um cartograma onde o circuito turístico aponta para um horizonte de sustentabilidade, com a emergência de um território complexo, multidimensional, que merece reapropriações e reterritorializações. O cartograma que sintetiza os resultados é apresentado a partir de três experiências escolhidas entre aquelas que apontam para os mais elevados níveis de sustentabilidade.

\section{Ponto 1 - Tradições revisitadas - Espaço Romanha}

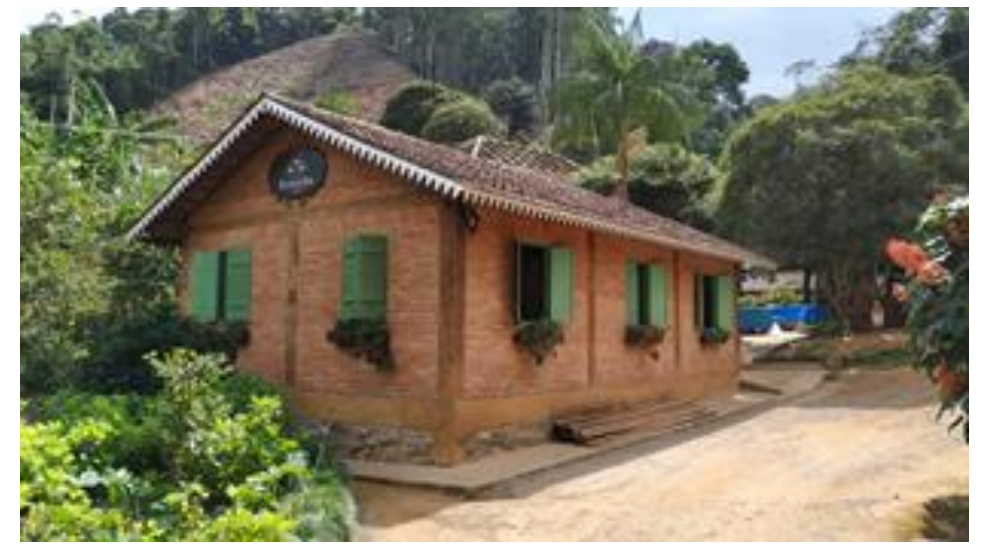

Figura 5 - Espaço Romanha
Neste ponto encontra-se uma das atividades exemplares do desenho e da concepção inicial do Circuito Caravaggio: 0 espaço Romanha (Figura 5). Trata-se de uma área de aproximadamente $500 \mathrm{~m}^{2}$,

onde se localizam algumas edificações com arquiteturas tradicionais e estabelecimentos comerciais. Uma antiga casa dos imigrantes italianos divide espaço entre residência e mostruário de móveis de madeira, construídos a partir de troncos e galhos de árvores secas. Toda a produção moveleira é artesanal e produzida em uma pequena marcenaria nos fundos da propriedade.

A antiga casa dos imigrantes divide espaço com um restaurante que serve comidas típicas regionais, uma fábrica de produção artesanal de vinhos e licores e um sobrado construído com materiais de um antigo sobrado abandonado. Em cada ponto deste estabelecimento é possível identificar forte empenho em manter a cultura e tradição regional viva. Nota-se, por exemplo: pratos típicos no restaurante; construções que mantêm a arquitetura tradicional local e produção de fermentado de jabuticaba, visto 
que os primeiros imigrantes, quando chegaram, não tinham uvas para produzir vinho e então, fermentavam jabuticaba.

\section{Ponto 2 - Turismo, cultura e inovação - Rampa de Voo Livre}

A rampa "Amauri Fernandes" ou simplesmente "Rampa de Voo Livre" (Figura 6) localizase no Circuito Caravaggio a oito quilômetros do centro do município. Seu acesso se dá, basicamente, por estrada de chão batido em bom estado de conservação, onde placas indicam o caminho até o mirante e é possível contemplar a vista panorâmica do vale do Caravaggio.

Deste ponto é também possível avistar, à noite, clarões de cidades distantes a cerca de $60 \mathrm{~km}$, como Colatina/ES. O topo da rampa conta com exatos 915 metros de altitude. Atualmente, é cobrada uma taxa de $\mathrm{R} \$ 3,00$ por pessoa para entrada no local, que funciona nos finais de semana, principalmente, para fins turísticos e para prática de voo livre de parapente, de 07:00h às 17:00h.

A administração do espaço e a organização das atividades de voos são realizadas pela VOLARE (escola de voo livre de Santa Teresa/ES), sendo possível realizar voos duplos com profissionais habilitados, pelos quais é cobrado o valor de $\mathrm{R} \$$ 150,00 .

Estruturalmente, a rampa conta

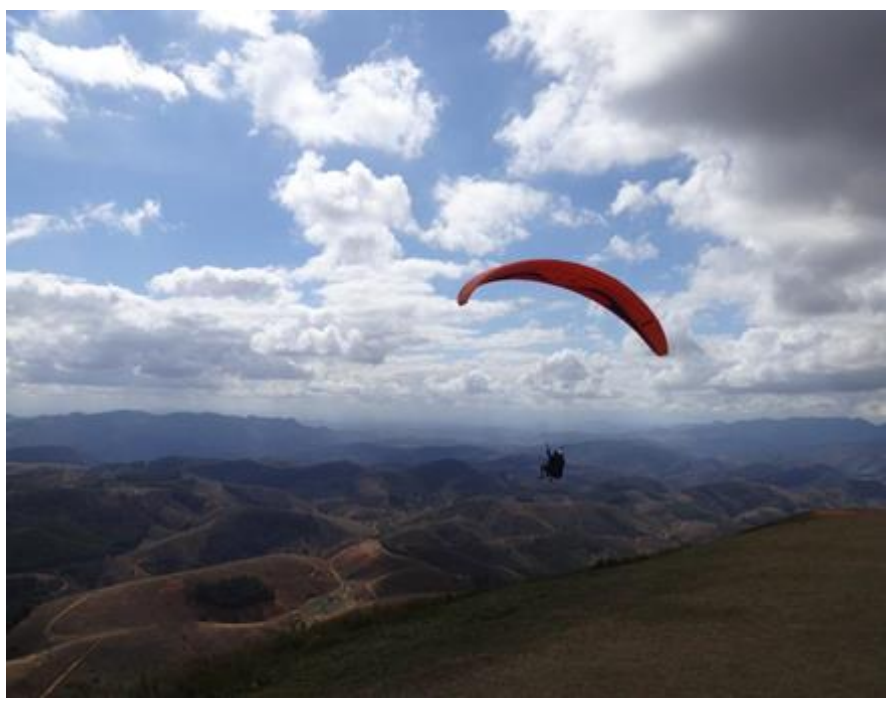

Figura 6 - Decolagem vista da Rampa de Voo Livre com ampla área gramada, estacionamento ao longo de sua vertente, banheiros e um pequeno bar para apoio aos visitantes. 
Em uma perspectiva de modernização e sustentabilidade, esta experiência se destaca na medida em que os elementos arquitetônicos e os princípios construtivos revelam cuidados e preocupações com a paisagem e a qualidade dos fatores culturais ali introduzidos.

\section{Ponto 3 - Águas do passado, do presente e do futuro: Country Clube}

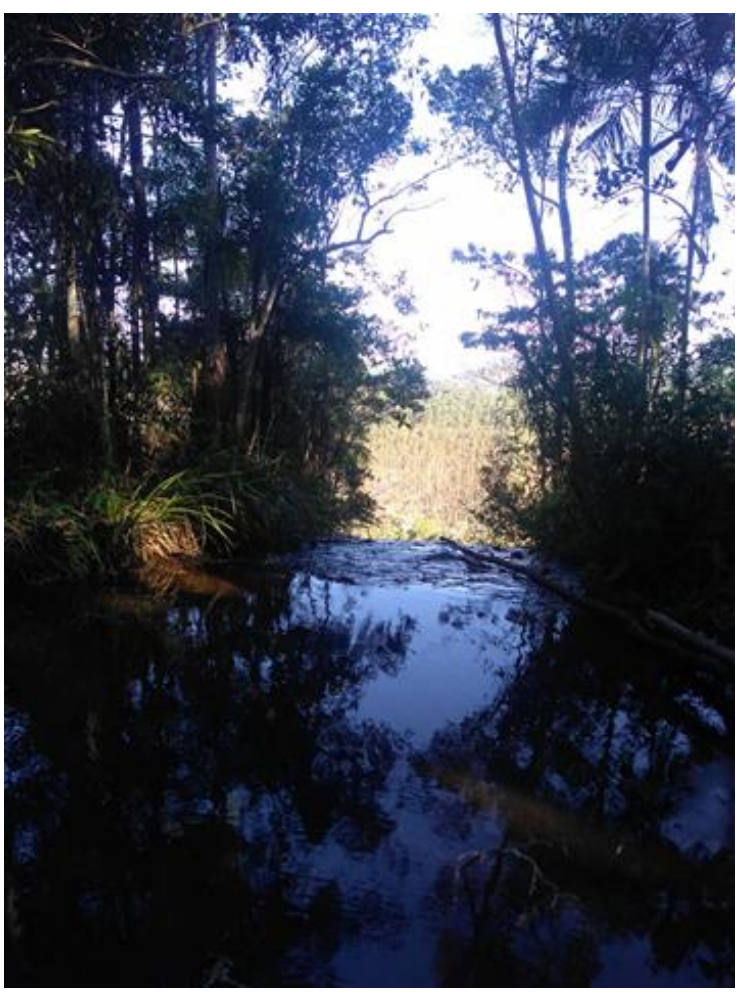

Figura 7 - Curso d'água - Country Club

Um curso d'água atravessa o território de um antigo clube, criando um cenário composto por quedas d'água e mata atlântica preservada (Figura 7). Outrora um lugar frequentado por moradores da região serrana e metropolitana do estado assim como associados do clube, o lugar recebe atualmente fraca visitação e está mantido por uma família que se responsabiliza pela limpeza e guarda do local.

O clube, inicialmente frequentado por parte da elite capixaba, hoje parece esquecido pela comunidade local. Apesar de compor o Circuito Caravaggio, o estabelecimento não conta com nenhum empreendimento recente.

Contudo, esta é a experiência que parece mais virtuosa do ponto de vista do desenvolvimento sustentável da região, merecendo, segundo nossa análise, uma maior atenção do poder público, no sentido de fazer uma reserva de espécies nativas no espaço ora ocupado por vegetação exótica. Há possibilidade para reconstituição do 
bioma natural, agregando renda para família que reside no local, através da valorização da preservação do bioma natural.

\section{Proposições: da sustentabilidade possível à participação necessária}

A proposta turística que dá origem à criação do Circuito Caravaggio, coloca um forte acento nas tradições da colônia italiana presente no local e sem dúvida é um fator que agrega valor à produção familiar.

Por aí, encontramos um nível de sustentabilidade que corresponde ao segundo tipo descrito por Pearce em seu quadro de referência. Trata-se de uma proposta de sustentabilidade fraca, onde os recursos são conservados, há uma modificação do crescimento econômico, a cultura ganha um valor instrumental, e é possível que ocorra uma equidade inter e intrageracional.

No caso da Rampa de Voo Livre, a proposta turística ganha um viés de modernidade, com força para atrair segmentos de população diferentes daqueles que se interessam principalmente pelas tradições. Então, a força modernizadora de uma prática esportiva se alia aos propósitos do turismo com base nas tradições e o desenvolvimento ocorre em um nível de sustentabilidade forte, ainda segundo a classificação de Pearce. Os recursos são preservados, a atividade não produz crescimento populacional, sua continuação depende da manutenção das condições ecossistêmicas; embora haja um investimento empresarial, o nível de interferência na paisagem é pequeno e os grupos que frequentam são, via de regra, grupos conscientes da questão ambiental.

É na terceira experiência, no entanto, que encontramos os maiores desafios e a maior potência para a efetivação de uma proposta de desenvolvimento com sustentabilidade muito forte, a depender de um esforço associativo e de gestão por parte do poder público. Na cachoeira do clube campestre e em seu entorno, a recuperação da mata nativa, com recomposição das espécies nativas pode fazer emergir um forte valor intrínseco da natureza, com reduzida escala da economia. Provavelmente é este o 
território mais propício ao desenvolvimento de estratégias coletivas de recuperação de espaços naturais, com um projeto de substituição da vegetação exótica por vegetação natural.

Tal projeto poderia ser desenvolvido por instituições educativas locais, contando com a participação de especialistas em ecossistemas, em parceria com setores progressistas da iniciativa privada e sensíveis aos "valores verdes" da economia; a participação cidadã promovida em fóruns de desenvolvimento em todos os níveis da administração pública podem levar à construção de uma "experiência modelo" que, além dos ganhos pontuais, pode também servir de plataforma para a ampliação da consciência ambiental e, consequentemente, à regulação coletiva dos fatores que ameaçam o território.

Na pesquisa aqui relatada adotamos a noção de sustentabilidade como utopia para o século XXI, como força social capaz de opor-se ao industrialismo desenfreado em todos os setores das atividades humanas e seus respectivos corolários de impactos negativos sobre a continuação da vida. Assim, concluímos que o Circuito Caravaggio é uma criação compatível com as políticas de desenvolvimento territorial sustentável para o mundo rural, justificando abordagens construtivas no âmbito das políticas públicas, cada vez mais democráticas e participativas.

\section{Referências Bibliográficas}

CMMAD. Comissão Mundial sobre Meio Ambiente e Desenvolvimento. Nosso futuro comum. Rio de Janeiro: Editora da Fundação Getúlio Vargas, 1991.

HAESBAERT, Rogerio. O Mito da Desterritorialização: Do Fim dos Territórios à Multiterritorialidade. Rio de Janeiro: Bertrand Brasil, 6 ed. 396p. ISBN: 978-85-2861061-1. 2011.

MATTOS, Carlos Alberto Sangali de; NUNES, José Luiz; SOBRINHO, Daiane Pereira. Planejamento e Programação de Ações - Santa Teresa. Programa de Assistência Técnica e Extensão Rural - Proater. 33p. 2013.

MONTEIRO, Isabel de Carvalho. A produção histórica do discurso do desenvolvimento sustentável: origens, tendências e desafios. Arquivo Jurídico, v. 2, n. 2, jan/jun 2012. 
PRADO FILHO, Kleber; TETI, Marcela Montalvão. A cartografia como método para as ciências humanas e sociais. Barbarói, n. 38, p. 45-59, 2013.

STOFFEL, Jaime Antonio; COLOGNESE, Silvio Antônio. O desenvolvimento sustentável sob a ótica da sustentabilidade multidimensional. FAE, Curitiba, v. 18, n. 2, p. 18 37, jul./dez. 2015.

SLPC. Página Web de São Lorenço Pousada \& Cerimonial. Disponível em https://www.pousadasaolourenco-es.com.br/circuito-caravaggio. Acesso em 16/02/2020.

MARINO, T.; DOURADO, F.; AMARAL, C.; XAVIER-DA-SILVA, J. Geotechnologiessupporting regular surveysandemergencyeventson Rio de Janeiro GeologicalSurvey - A case ofstudy. Proceedingsof World LandslideForum 3, 2-6 June, Beijing. 2014.

Data de Submissão: 18/02/2020

Data do Aceite: 01/03/2021 